\title{
Reagan vs. Gaddafi: la operación "El Dorado Canyon" y la prensa española (1986)
}

\author{
Coral Morera Hernández \\ Universidad de Valladolid \\ cmorera@hmca.uva.es
}

Recibido: 17 de junio de 2014

Aceptado: 17 de septiembre de 2014

\begin{abstract}
Resumen
La operación "El Dorado Canyon" fue una intervención bélica puesta en marcha en EE.UU. para acabar con el dictador árabe Muammar al-Gaddafi. Analizamos la cobertura realizada por tres periódicos españoles, La Vanguardia, $A B C$ y El País, a través del análisis de contenido, cuantitativo y cualitativo, para conocer qué actitud adoptaron y si recurrieron a un enmarcado de acontecimientos en la descripción de los hechos.
\end{abstract}

Palabras clave: Reagan; Gaddafi; El Dorado Canyon; framing; prensa.

\section{Reagan vs. Gaddafi: "El Dorado Canyon" operation and the Spanish press} (1986)

\begin{abstract}
The "El Dorado Canyon" operation was a military intervention launched for the U.S. to murder to the Arab dictator, Muammar al-Gaddafi. We analyze the coverage of three Spanish newspaper, La Vanguardia, $A B C$ and El Pais, through content analysis, quantitative and qualitative, to know the attitude and the news framing adopted by the press on the events description.
\end{abstract}

Key words: Reagan; Gaddafi; El Dorado Canyon; framing; press.

\section{Referencia normalizada:}

Morera Hernández, C. (2014) Reagan vs. Gaddafi: la operación “El Dorado Canyon” y la prensa española (1986). Historia y Comunicación Social. Vol. 19. Páginas 355-374.

Sumario: 1. Introducción. 2. El terrorismo y la complacencia europea por La Vanguardia. 3. Europa y el antiamericanismo por $A B C$. 4. De espaldas al derecho internacional por El País. 5. Conclusiones. 6. Referencias bibliográficas. 


\section{Introducción}

La operación "Cañón el Dorado" nos remite a la acción militar puesta en marcha por EE.UU. el 15 de abril de 1986 y ejecutada por la Fuerza Aérea, la Armada y la Infantería de Marina estadounidenses, que consistió en el bombardeo de las ciudades libias, Trípoli y Bengasi. Aquel conflicto se convirtió en un duelo personal entre el entonces presidente republicano, Ronald Reagan, y el coronel libio, Muammar al-Gaddafi, y fue motivo de polémica, y por supuesto de propaganda, como cualquier otro conflicto bélico, y quizá más por estar enmarcado en la Guerra Fría y por sus dos protagonistas. La distancia temporal, y el distinto final seguido por los actores, dota al presente trabajo de un atractivo interés, tanto periodístico como histórico. Nos permite además conocer cómo se han abordado algunos conflictos bélicos en el mundo contemporáneo.

No hay estudios académicos que se hayan ocupado de la cobertura de aquel enfrentamiento ${ }^{1}$, por lo que el presente trabajo resulta pertinente. El conflicto bélico recibió un interés amplio en los diarios seleccionados para el trabajo, La Vanguardia, ABC y El País, los de mayor difusión del momento, y ello se desprende por el elevado número de primeras páginas que acaparó, y sobre todo, por el número de editoriales publicados al efecto.

Para contextualizar los hechos, incluimos unos someros apuntes sobre los antecedentes. El suceso bélico que se desarrolló entre Estados Unidos y Libia en el año 1986, se enmarca en un conflicto cuyo precedente se producía una década antes, en noviembre de 1972, cuando Libia decretaba la prohibición a EE.UU. de sobrevolar el espacio aéreo en ciento ochenta y cinco kilómetros alrededor de Trípoli. Pero el origen y la secuencia de los enfrentamientos que libraron los dos países debe establecerse en el año 1969.

En aquel año, el coronel Muammar al-Gaddafi encabezó un levantamiento militar para derrocar a la monarquía, y Libia pasó a convertirse en el foco de numerosos conflictos. Coincidiendo con el secuestro de los rehenes en Teherán en noviembre de 1979, la embajada de los EE.UU. en Trípoli fue incendiada por una multitud que vitoreaba al ayatollah Jomeini. Dos años después, y con Ronald Reagan ya en el poder, en el verano de 1981, dos aviones estadounidenses "F-14" derribaron dos aparatos libios "SU-22" en el Golfo de Sirte o Golfo de la Sidra: EE.UU. dijo que los aviones libios habían disparado primero. En noviembre de ese mismo año, la Casa Blanca clausuró la embajada libia en Washington y expulsó a su personal, acusándole de contravenir las normas diplomáticas. A partir de ese momento el Golfo de la Sidra se convirtió en un foco de conflictos entre los dos países. En febrero de 1983 varios reactores estadounidenses derribaron dos "MIG-23" libios que se habían aproximado al portaaviones Nimitz. El Mediterráneo se había convertido en el escenario en el que tenían lugar ataques terroristas, secuestros, bombardeos y una escalada bélica de considerables proporciones. Gaddafi cumplía su amenaza de luchar "a muerte" por proteger un golfo que consideraba de su propiedad. 
Los enfrentamientos se sucedieron y dos años después, en diciembre de 1985, veinte personas fueron asesinadas en dos atentados perpetrados en los aeropuertos de Roma y Viena. Reagan acusó directamente a Libia de complicidad en los mismos y decretó un embargo económico. En enero de 1986 empezaron las maniobras estadounidenses en el Mediterráneo frente a las costas de Libia. Durante todo el año la flota norteamericana se iría adentrando en el Golfo de la Sidra mientras Libia seguía reclamando su soberanía. Gaddafi ordenó los ataques a través de misiles y cohetes en nombre de lo que él consideraba "la línea de la muerte".

El detonante que marcó la "Operación el Dorado Canyon" fue un atentado terrorista atribuido a Libia y de tinte antiamericano, perpetrado el cinco de abril de 1986 en una discoteca de Berlín frecuentada por norteamericanos, con más de doscientos heridos: sesenta y tres de ellos estadounidenses. Diez días después las tropas norteamericanas bombardeaban distintos puntos de Trípoli y Bengasi. Diez años de enfrentamientos habían ido envenenando las relaciones entre Gaddafi y EE.UU.: empezaba la crónica de un conflicto anunciado.

A pesar de la complejidad del conflicto, la estrategia de Reagan resultaba simple: el uso de la fuerza, (Reagan, 1991: 544-549). De forma calculada, el presidente republicano decidió castigar militarmente al régimen del coronel Gaddafi con o sin ayuda de los aliados europeos. La justificación del presidente republicano pasaba por considerar que Gaddafi aglutinaba un odio contra Occidente en general y contra los Estados Unidos en particular; si uno de los focos del terrorismo internacional se encontraba en Trípoli, había que enfrentarse a él: "La legítima defensa no es un derecho, es una obligación; y esto es legítima defensa"2.

La metodología que ha atendido a nuestro estudio se fundamenta en la producción de noticias seguida por la Agenda Setting, (McCombs y Shaw, 1972) concretamente el framing, news framing, o encuadres noticiosos ${ }^{3}$. El framing se encarga de enfocar el núcleo principal de la historia y encuadrar dicho núcleo desde un ángulo determinado. El encuadre encierra, por tanto, una visión concreta de la historia y no otra, lo que supone una limitación "de las visiones sobre los temas u objetos" (Igartua y Humanes, 2004: 257). No obstante, los medios recurren al framing como herramienta para reducir la cantidad y complejidad de los asuntos de la actualidad, es decir, no necesariamente con la intención de desviar la atención de los temas o alterar su contenido. Nos interesa localizar cuándo hay framing, y cuándo ese enmarcado se traduce en una simplificación temática que sí busca una alteración del producto noticioso.

Nuestro estudio aborda un análisis de contenido de carácter cuantitativo y cualitativo. En primer lugar, planteamos un estudio abierto, sin marcos predeterminados, que nos permita localizar el enmarcado del tema. En segundo lugar, atendemos a si la cobertura es temática o episódica, según lo plantean Iyengar y Ottati (1994). Una cobertura es temática cuando es abstracta y compleja, y es episódica cuando remite a la descripción de los acontecimientos.

La tercera fase de nuestro análisis remite al Frame mapping propuesto por Miller y Riechert (2003: 115-120). Este estudio aborda cuatro estados: 
Lista de conceptos presentes en las noticias, titulares, especiales. También se incluyen los protagonistas de las noticias y las fotos.

El número de veces que aparecen conceptos claves o recurrentes.

Cómo se agrupan los conceptos clave para establecer dimensiones.

Identificación de cada dimensión con el encuadre noticioso correspondiente.

Llevamos a cabo una exploración cualitativa de los textos centrando nuestro estudio en el discurso emitido por los corresponsales y en el posicionamiento oficial de los diarios a través de los editoriales. Para el análisis de estas piezas, hemos seguido la clasificación propuesta por Santamaría y Casals (2000: 274-277).

Se han analizado un total de ciento catorce informaciones correspondientes a la cobertura de los diarios desde el inicio de la crisis, en marzo de 1986, hasta el enfrentamiento bélico, en abril de aquel año. No observamos diferencias significativas entre las tres cabeceras excepto por el mayor número en La Vanguardia como se observa en la siguiente tabla de resultados cuantitativos.

\begin{tabular}{|c|c|c|c|}
\hline & $\mathbf{1}^{\text {a }}$ Página/Portada & Editorial & Noticias \\
\hline La Vanguardia & 7 & 7 & 35 \\
\hline ABC & 5 & 6 & 20 \\
\hline El País & 7 & 6 & 21 \\
\hline TOTAL & & & $\mathbf{1 1 4}$ \\
\hline
\end{tabular}

Los discursos principales encontrados son los siguientes: el terrorismo, la actitud de Europa y el uso de la fuerza en el caso de La Vanguardia. La denuncia contra la campaña antinorteamericana puesta en marcha en Europa y el elogio hacia los EE.UU. en $A B C$, y la condena explícita de Estados Unidos por su acción y un marcado europeísmo en El País.

\section{El terrorismo y la complacencia europea por La Vanguardia}

Tres grandes temas centraron la cobertura de La Vanguardia acerca de la crisis entre Libia y EE.UU.: por una parte, el terrorismo como fenómeno que amenaza al mundo. En segundo lugar, se ocupó de la actitud de Europa ante los acontecimientos, de la falta de operatividad del Viejo Continente, que fue denunciada con mayor intensidad conforme avanzaba la crisis; y en tercer lugar, el uso de la fuerza de Reagan como única alternativa para frenar al dictador libio.

El nombre del especial fue:

La crisis en el Mediterráneo 
Con respecto al discurso dirigido contra Europa, al principio de la crisis el diario se mostró más descriptivo con la actitud europea, pero la escalada gradual de enfrentamientos entre los dos países provocó que el diario mostrase una denuncia más severa hacia la criminalidad del líder libio y menos complaciente con la prudencia de los europeos:

En realidad, la actual crisis en el Mediterráneo no es más que la prolongación de la crisis del "Achile Lauro", y los actuales acontecimientos han sido configurados por el desenlace de aquel caso. Cuando los aliados europeos se negaron a participar en un paquete de sanciones económicas en serio, Washington decidió que no le quedaba más remedio que actuar por su cuenta, y mediante la fuerza ${ }^{4}$.

Con respecto a la medida de fuerza adoptada por el presidente republicano, el diario catalán es claro. El hilo argumental pasó por contar qué estaba haciendo el republicano y por qué. Reagan es el mismo de siempre y está dispuesto a librar cuantas batallas requiera el final de la Guerra Fría y cuantos hechos alteren la paz internacional como es el caso del terrorismo. Reagan ha tomado represalias contra Trípoli porque se ha cansado de que Gaddafi siga patrocinando acciones terroristas contra EE.UU., represalias, por otra parte, que no coinciden con las llamadas a la prudencia y la moderación que solicitan los europeos. No es lucidez lo que le falta a Reagan en cuanto al conflicto de Libia sino que ha llevado la firmeza a cotas no alcanzadas hasta entonces. Simplemente había llegado el momento de frenar a quien el republicano consideraba un "payaso imprevisible" (1991: 746).

Los dos bandos en conflicto son Estados Unidos, que ha convertido en hechos sus propósitos de intervención bélica, y el coronel Gaddafi, llamando a los países árabes a emprender la "guerra santa" contra el "agresor". Reagan lo tiene claro y elige destinatarios en torno a la crisis: el propio Gaddafi, EE.UU., la URSS y sus aliados europeos:

El Gobierno de Washington ve diversos beneficios en su decisión: 1) Demostrar a Gaddafi que sus acciones no son impunes, y que eventualmente siempre hay un precio que pagar; 2) Demostrar al pueblo norteamericano que Reagan no se limita a "ladrar", sino que de vez en cuando también muerde: 3) Demostrar a la URSS que Estados Unidos ya no se queda con los brazos cruzados cuando sus intereses están en juego; demostrar a los aliados europeos que, tal como les había advertido, su falta de colaboración en la lucha contra el terrorismo lleva a este tipo de situaciones ${ }^{5}$.

La estrategia que había diseñado Reagan para la "Operación Cañón El Dorado" incluía: la tecnología, la diplomacia, la inteligencia y la política. A corto plazo parece que sólo había triunfado en la primera, fracasando de forma espectacular en lo referente a la diplomacia:

1) un resurgimiento de la ola de antiamericanismo en Europa, como lo indican las manifestaciones de protesta de estos días; 2) el deterioro de las relaciones con la URSS, 3) la posible cancelación o aplazamiento de la cumbre Reagan-Gorbachev prevista para esta primavera-verano; 4) la imagen de desunión que ha dado la Alianza Atlántica; 5) el fomento de la desconfianza hacia aliados como España y Francia que no forman parte de la estructura militar integrada de la Alianza Atlántica, y que se negaron a prestar su espacio aéreo para esta misión 6 . 
No observamos una justificación vehemente sobre la utilización de la fuerza por parte de Reagan; el diario lo presentó como la única opción y la más eficaz para frenar el terrorismo. A pesar del deterioro de imagen que aquello supondría sobre su persona, el republicano parece, para la cabecera, más interesado en ser coherente con su política y tomar medidas contundentes que en salir airoso ante la opinión pública internacional ${ }^{7}$.

Nos ocupamos ahora del discurso editorial. La argumentación de La Vanguardia nos parece clara, directa, sencilla y uniforme: no se detecta la presencia de distintos editorialistas. Los núcleos versaron sobre el terrorismo, la inoperancia europea y Gaddafi, personaje este sobre quien el rotativo advirtió de lo errático de las valoraciones que se estaban emitiendo. El coronel libio está siendo juzgado como un personaje extravagante y pintoresco, cuando para el diario, se trataba de alguien peligroso.

Antes de la intervención estadounidense, el diario catalán describió así los hechos. Se trata de que el Mare Nostrum siga en orden y de que los intereses de los occidentales estén a salvo. Se trata de frenar a un dictador árabe antioccidental armado con misiles soviéticos. Se trata también de uno más de los pulsos que mantienen la URSS y EE.UU. en su lucha de poder en lo que fueron los últimos coletazos de la Guerra Fría y se trata de constatar cómo Europa adopta una actitud de pusilanimidad ante aspectos que le afectan directamente ${ }^{8}$.

El terrorismo es un problema de extrema gravedad y se confirma que los actos terroristas sobre población civil empiezan a ser algo normal, ejecutado por personal formado en territorio libio. El fenómeno del terrorismo se extiende por el Viejo continente como una "plaga" y en Libia, cohetes estratégicamente colocados apuntan al flanco sur de Europa ${ }^{9}$. La VI Flota es la única fuerza capaz de garantizar la libre circulación por el Mediterráneo, el lugar del que Gaddafi dijo que "se convertiría en un mar de sangre".

Describió con claridad, y decepción, el escaso consenso entre Europa y EE.UU. para solucionar esta crisis desde el principio: "sin que ello suponga costes excesivos para quienes desean sobre todo nadar y guardar la ropa, es decir, comerciar con Gaddafi y protegerse con la alianza y el poderío americano". La crítica hacia Europa fue contundente y se mantuvo en todas las piezas: "La tensión no se resolverá a cañonazos, pero tampoco hallará solución practicando la política del avestruz"10.

Recordaba La Vanguardia que los grandes conflictos del siglo XX en Europa comenzaron con incidentes "que parecían irrelevantes". La situación es grave para el diario; es un momento tenso de la Guerra Fría que puede desencadenar un enfrentamiento bélico entre los dos bloques:

Detrás del coronel libio se esconden muchas más cosas que un ejército de 75.000 hombres. Trípoli es apoyado por la mayoría de los países árabes y por, prácticamente, todo el bloque que gira alrededor de Moscú. Un ataque a Libia nos situaría en la peligrosa tesitura de enfrentar en el Mediterráneo a los dos bloques ${ }^{11}$. 
No sirve, para el diario, la cuestión de que Gaddafi sea un personaje cuya conducta no se ajuste "a los parámetros reconocidos internacionalmente". Nadie quiere una guerra, señaló el diario, pero no se puede disculpar a Gaddafi apelando a que se trate "de un personaje pintoresco y extravagante"12. Para el rotativo catalán el asunto fue algo más serio, y su análisis, también. Ni EE.UU. puede seguir permitiendo que sus aviones sean objeto de atentados ni sus ciudadanos víctimas del terror cuando viajan por el mundo, ni Europa puede permanecer impasible y absorta "en distingos sobre si Washington es el que provoca el conflicto en el Mediterráneo". Un análisis que no ahonde en estas variables es errado.

Europa se encuentra ante una situación complicada peligrosa, y la crisis entre Trípoli y Washington no es cosa de dos: son más los países implicados. Reagan ha venido advirtiendo desde hace años de que "Gaddafi es el principal responsable del incremento del terrorismo y la violencia". Europa ha actuado mal, ha sucumbido a corrientes de opinión interesadas; se han desoído las advertencias, se han ninguneado los datos, y sólo proceden a reunirse en La Haya cuando Reagan anuncia su propósito de intervenir. "La lamentable lentitud" de la CEE "no justifica la intervención unilateral" pero facilita su comprensión según el editorial.

Pocas veces ha sido tan evidente el contraste entre los signos de debilidad, de insolidaridad de los europeos, y la firmeza - excesiva - de los norteamericanos. La flojedad, la falta de práctica reacción, la ineficacia de los primeros en todos estos años de continuas provocaciones han envalentonado al jefe libio en lugar de amansarlo ${ }^{13}$.

Una vez se produjo la intervención estadounidense, las imágenes, "tristes y repugnantes" del ataque estadounidense, son "como las de todas las guerras y de todos los conflictos armados" 14 . Y apela a la propaganda y a la catadura moral del líder libio para explicar dichas imágenes. Pero no advertimos una justificación, ni siquiera un respaldo, ni implícito ni explícito, es decir, condenó las formas pero no el fondo, y sólo consideró justificado discutir sobre la oportunidad del bombardeo.

Vuelve a colocar al terrorismo como un fenómeno grave, para el mundo y para Europa. Y el problema está precisamente aquí, en el Viejo Continente, en su lentitud, su inoperancia, sus diagnósticos: "La tesis de que Gaddafi es un personaje impredecible y con planteamientos políticos que nada tienen que ver con los nuestros y, por lo tanto, no hay que provocarle, es una tesis que no soporta un análisis serio"15. Si triunfa la propaganda de Gaddafi en Occidente no hemos entendido nada del conflicto que se cierne sobre el Mediterráneo.

El último editorial de nuestro análisis aborda la crítica más rotunda:

La táctica es la misma que la empleada todos estos años. El enemigo es el imperialismo yanqui, pero, de paso, se involucra a todo el Occidente. Los italianos porque son los más próximos. (...) De este modo y, aunque sea en un tono de menos ínfulas, se pretende dictar la política exterior y de alianzas de las naciones democráticas. A este paso Trípoli se erigiría en árbitro del concierto de las naciones ${ }^{16}$.

Así las cosas, no tenemos derecho a lamentarnos desde Europa: no se ha hecho nada, ha habido torpeza e inoperancia; si hubiera habido un mínimo de cohesión no 
estaríamos ante una situación "demencial", ni se hubieran producido "las réplicas que ahora lamentamos"17. Da las cifras cuantitativas de los muertos en actos terroristas en Europa de origen estadounidense. El análisis sigue profundizando al señalar a todos los protagonistas: la situación estratégica de Libia, la figura de Gaddafi "el mascarón de proa del antiamericanismo", la verborrea del dictador, los excesos de Reagan "que no tuvo pelos en la lengua". Esto es todo lo ocurrido "entre un régimen democrático conservador, de línea dura, y una dictadura fascistoide" y la dejadez de otros", hemos llegado a esta situación y ahora "vienen las prisas por reunirse" $"$.

\section{Europa y el antiamericanismo por $A B C$}

En esencia $A B C$ trató los mismos temas que La Vanguardia aunque el tono se percibe algo diferente en la forma y la cantidad, no así en el fondo. El núcleo argumental fue contar lo que estaba haciendo EE.UU. y por qué. El nacimiento del terrorismo internacional con sede en Oriente Próximo y América Central y disfrazado con el nombre de movimientos de liberación nacional es un asunto de extrema gravedad. Los especiales fueron:

\section{Tensión bélica en el Mediterráneo}

Guerra EE.UU.-Libia

\section{Conflicto EE.UU.-Libia}

La tensión internacional se había agravado pero el responsable no era Reagan sino Gaddafi. Las maniobras estadounidenses eran la respuesta a años de amenazas y actos terroristas contra ciudadanos norteamericanos. Reagan se había cargado de razones y paciencia antes de dar un paso como este y su estrategia se había calculado con pulcritud: maniobras en las aguas reclamadas por Gaddafi, dotarse de una gran fuerza aeronaval para controlar la zona y tolerar hasta seis misiles libios contra sus fuerzas ${ }^{20}$.

Estados Unidos no pretende provocar ni humillar; necesita dejarle claro a Gaddafi que la navegación en aguas internacionales es libre y que no tiene derecho a improvisar las fronteras internacionales ni a apropiarse de un mar, por lo tanto, es él quien traspasa la "línea de muerte" y no al revés.

No podía presentarse a EE.UU. como el provocador de la tensión mundial sino como la víctima paciente que cumplía sus advertencias y castigaba a los desestabilizadores. El silencio inoperante de los aliados europeos va produciendo una quiebra entre las propuestas de Reagan y el resto de la comunidad internacional:

Una vez hallada la conexión libia en el atentado contra la discoteca berlinesa, Reagan pidió a los aliados europeos apoyo para combatir ese foco terrorista. Y lo planteó más o menos en estos términos: o bien decidimos todos medidas conjuntas diplomáticas y económicas contra Libia, aislándola, o me veré obligado a actuar por mi cuenta, ya militarmente. Elegid, pues no puede consentirse que Gadafi siga 
adelante matando norteamericanos y también europeos, inocentes. Y para demostrar que iba de veras, comenzó a reunir una poderosa fuerza ante $\mathrm{Libia}^{21}$.

La acción militar se podía condenar pero, según el diario, no a costa de la impunidad de Gaddafi y sus vinculaciones con actos terroristas. Dadas las dimensiones del terrorismo, $A B C$ criticó a los medios de comunicación por haber puesto en marcha una campaña de propaganda que no condenaba el terrorismo de Gaddafi y que sin embargo fomentaba el sentimiento antiamericano como algo natural. Esa complacencia y complicidad de muchos medios de comunicación fue censurada por el diario: la advertencia europea de recordarles a los norteamericanos que el Mediterráneo era un mar europeo y pedirles que se marchasen, no era una argumentación solvente ${ }^{22}$.

Lo que ha hecho Reagan ha sido bombardear Libia y bombardear a sus aliados. EE.UU. es el país que disfruta de la hegemonía mundial y como tal debe garantizar la paz aunque el siempre condenable empleo de la fuerza sea la última de las opciones. La cuestión es que no parece que a Reagan le hayan quedado muchas más opciones; ése entendió el diario que debía ser el punto de partida desde el que analizar el conflicto $^{23}$.

Sobre el discurso editorial del rotativo madrileño, el protagonismo es para Estados Unidos. Encontramos alguna pieza que mantiene un discurso editorial algo diferente desde el punto de vista discursivo, o si se quiere, que rebaja la intensidad de los comentarios. No hallamos, por tanto, la misma uniformidad que en La Vanguardia. La postura ideológica está muy vinculada con la Guerra Fría y con la oposición al gobierno del momento.

En el primer editorial de nuestro análisis y antes del bombardeo estadounidense, el diario se retrotrae al 1973, a lo que llama "la guerra del Ramadán" y al "hipernacionalismo de Gaddafi”, el nacionalismo árabe. Está muy presente la Guerra Fría en los textos, está constantemente aludiendo a la URSS, a cómo ha inoculado "la violencia de exportación", la semilla de ciertos comportamientos, que han surtido más efecto en Argelia y Libia.

Tras hacer un largo análisis del tema terrorista y de la figura de Gaddafi y del apoyo soviético, planteó una crítica contra la respuesta norteamericana: "La alternativa bélica por la que implícitamente optaba ayer el mando militar norteamericano no sólo suscitaba peligros y riesgos de la mayor escala, (...) sino que depara un espectáculo moralmente poco edificante". De hecho, "La acción de la VI Flota en el golfo de Sidra, (...) se presenta objetivamente emparentada con la del bombardeo israelí de Túnez, el pasado mes de octubre". Porque para poner fin a regímenes que apoyan al terrorismo, "no debe utilizarse la misma inadmisible moral que el terrorismo utiliza" 24 .

En el segundo editorial los textos son mucho más ácidos; no persiguen la información sino el posicionamiento, porque "La Libia de Gadafi no tiene justificación moral ni jurídica para trazar un límite arbitrario sobre el mar". El respaldo a los EE.UU. no es ambiguo: no han disparado primero, simplemente han respondido a los misiles libios. 
No hace falta recordar las incursiones del "atrabiliario coronel a lo ancho de medio mundo": Chad, Ceuta y Melilla, la creación de comandos terroristas, "los ejemplos se multiplican". Por tanto, no es momento para "el antiamericanismo primario" ni para "el simplismo antiárabe". Europa, una vez más se mueve torpemente, confundiendo a las naciones solventes con "un aventurero frío e inverecundo", como si fuera un líder del mundo árabe.

En la siguiente pieza de análisis, el editorial aplaudió el respaldo recibido por EE.UU. por parte de la OTAN, quienes "parecen definitivamente decididos a neutralizar el foco de constante promoción del terrorismo que representa el coronel Gadafi". Y aprovechó para criticar a España e Italia, pero sobre todo al gobierno español por adoptar una actitud que se desmarcaba de la Alianza Atlántica ${ }^{25}$.

Ante el primer bombardeo estadounidense, el diario se jactó al hablar de "guerra" en el elocuente título y respaldó a los EE.UU. ${ }^{26}$. Ha actuado de forma "contundente" y "rápida": "tan sólo veinte minutos de ataque". El atentado en la discoteca en Berlín de autoría libia ha sido el detonante. Señaló que las respuestas militares eran condenables, pero que no había otra opción: era necesario defender los intereses occidentales y en eso se esmeran en La Haya los ministros de Exteriores: "en ofrecer a los Estados Unidos una posición común". Pero frente a ese empeño, movimientos "próximos a la Internacional Socialista" defienden actuaciones que van contra los intereses de Occidente. Las argumentaciones no son válidas para el diario: hablar del Mediterráneo como un mar europeo "como si los norteamericanos debieran abandonarlo" no rezuma sentido común. Algo grave está pasando en el mundo, y gira en torno al fenómeno del terrorismo. Vemos una similitud argumental con el diario catalán, pero con un posicionamiento ideológico más nítido y menos ponderado.

Hallamos dos temas en el siguiente editorial: EE.UU. y el gobierno español ${ }^{27}$. Con respecto al primero de ellos, la argumentación se centra en ensalzar a EE.UU. como nación, su papel en el mundo, su liderazgo y la justificación de la intervención. "La violencia, en teoría, es siempre condenable" lo que según el diario no excluye que en alguna circunstancia pueda resultar "ineludible" para quien ejerce "el liderazgo mundial" y es el garante de la paz. Hubiera sido deseable una negociación, pero no la ha habido, así las cosas, "la respuesta armada" mejor antes que después. Estados Unidos es "el primero de los aliados" y "la nación que garantiza la seguridad en Europa". Justifica a Reagan por la desidia europea:

No se hizo nada, salvo unas platónicas declaraciones, donde incluso se equiparaba a Libia y los EE.UU. (...) como si el comportamiento de Gadafi y de Reagan fuesen asimilables como entidades homogéneas ${ }^{28}$.

El mundo ha cambiado desde hoy para el diario, EE.UU. "utilizará la fuerza cuando lo crea indispensable". Y Europa se queda "a medio camino entre la firmeza de los gobiernos conservadores y la calculada ambigüedad que predica la Internacional Socialista". 
En el segundo tema entona una crítica al gobierno español, quien ha rebajado la intensidad de la crisis, mientras el presidente Felipe González ha seguido de vacaciones en Doñana, ha ocultado la visita de Vernon Walters, cuando las visitas de este a Roma, Londres, París y Bonn han sido hecho públicas.

En la última pieza analizada del diario, entonó una caricatura sátira para describir la crisis donde se dan cita todos los protagonistas ${ }^{29}$. Describió la anormalidad política de Gaddafi pidiendo a Italia y a España que prohibieran navegar en sus aguas a la VI Flota. "Es una de las más sorprendentes propuestas que se puedan formular a dos naciones soberanas, vinculadas a EE.UU. por una alianza militar". También se refirió a la humillación militar sufrida por Gaddafi "quien ha invertido, desde 1980, más de dos billones de pesetas" en maquinaria bélica. Aludió a la implicación soviética en los hechos. No podemos olvidar, según el diario, que estamos en la Guerra Fría: "nueve buques de guerra rusos, fondeados frente a Trípoli (...), se hicieron a la mar, como por casualidad, al atardecer del lunes catorce, pocas horas antes del bombardeo americano". Y por último, se refiere a la inoperancia europea, "Washington comprendió que sus aliados europeos se mueven con la torpeza de un elefante de doce patas, empeñado en curar la gangrena con agua oxigenada". Es una más de las contradicciones de los doce.

\section{De espaldas al Derecho Internacional por El País}

Los discursos principales del diario fueron: el intervencionismo norteamericano y la desestabilización mundial, la ola de patriotismo que sufre la opinión pública estadounidense y la victimización de Europa y Gaddafi. El especial del diario fue: GUERRA EN EL MEDITERRÁNEO ${ }^{30}$.

Se observan también imprecisiones en titulares o cuerpos informativos al referirse a que Estados Unidos ataca "de nuevo" 31 una base Libia, cuando en realidad se trataba del primer ataque norteamericano y así se cuenta en el cuerpo de la información, mientras que para los otros diarios fue descrito como un "contraataque".

No se detecta la profundización de análisis observada en los otros diarios acerca del fenómeno del terrorismo y la división de Occidente con respecto del mismo. Por lo tanto, no podemos analizar la cobertura del diario en torno a una secuencia de acontecimientos sino a un conglomerado de informaciones negativas sobre el presidente republicano. EE.UU. con su acción abusa de los más débiles, por eso bombardea las ciudades de noche cuando la aviación libia no vuela; y lo más grave, la desproporción de su acción, cuyo origen parece ser la reivindicación de un atentado que sólo costó la vida de dos personas:

El portavoz presidencial, Larry Speakes, informó al país por televisión del ataque a las 2.20 (hora peninsular española) y afirmó que se trataba de un acto legítimo de "autodefensa" por el atentado terrorista de la discoteca de Berlín Oeste, en el que el pasado 5 de abril murió un soldado norteamericano, y una ciudadana turca ${ }^{32}$. 
La línea argumental del diario se vio combinada con otros recursos fotográficos y semánticos, tanto la inclusión de fotografías sobre cómo había quedado Libia tras los bombardeos norteamericanos, o la fotografía del abrazo de Franco y Eisenhower de visita en España en 1959, así como titulares que sirvieran de apoyo al discurso principal en los que las palabras guerra y bombardeo están presentes de forma constante ${ }^{33}$.

En el discurso editorial de El País, el desafecto por EE.UU. y la vehemencia con que defendió Europa, le privó de un análisis más riguroso que no adoptara actitudes excesivas. Al igual que ocurre con $A B C$, hay un par de piezas que no parecen guardar similitud con el conjunto. Los títulos de los editoriales, aunque facilitan el posicionamiento del diario de cara al lector, parecen más propios de columnas o artículos de opinión y están más sujetos a golpes de efecto.

El nivel de valoración del primer editorial de nuestro análisis es elevado ${ }^{34}$. Acometió una pseudocondena hacia Gaddafi para entrar a fondo en una sentencia contra EE.UU.: emplea en ello la mayor parte del texto. El lenguaje es muy explícito, un número importante de adverbios, ocho en total, y bastantes adjetivos. No profundizó ni en el análisis, ni en los antecedentes ni en las consecuencias. EE.UU. era el culpable del conflicto, equiparado con Gaddafi, nos atrevemos a señalar que incluso peor, por llevar a cabo una acción temeraria en tiempos de paz, al margen del derecho internacional, que presenta como una acción defensiva, cuando en realidad "es utilizada por el Gobierno de Washington para objetivos que responden exclusivamente a su particular concepción de las relaciones internacionales". La administración Reagan ha actuado "en réplica al lanzamiento de seis misiles libios que no hicieron blanco", con un doble bombardeo. Se trata, según el diario, de una "acción claramente provocativa" y todo ello porque EE.UU. mediante "un juicio simplista, ha decidido que Gaddafi es el culpable número uno de todo el terrorismo en el mundo". La estrategia de Reagan:

Demuestra una peligrosa ignorancia de la realidad internacional y en particular del mundo islámico. Estados Unidos puede producir terror y callar muchas voces, incluso gubernamentales, pero, a la vez, siembran odio y resentimiento. De hecho, están estimulando las corrientes de fanatismo y desesperación que abonan precisamente el terreno para el terrorismo. Dispone de muchas armas y medios económicos, pero ha preferido el gesto arrogante a la gestión eficaz, debilitando así a los Gobiernos más sensatos y moderados. Su acción militar ahora culmina el agravamiento de una actuación plagada de fracasos ${ }^{35}$.

Y lo peor para el diario es su conclusión final: está poniendo en peligro a los países de la cuenca mediterránea, sobre todo a España y a Italia.

El segundo editorial analizado no destila los rasgos de valoración del anterior. Acometió un análisis más profundo y ponderado ${ }^{36}$. Libia es un factor de inestabilidad en el Mediterráneo y lo es por culpa de Gaddafi, "de sus excesos verbales", de "su bravuconería" y de su propaganda "llena de invenciones y exageraciones". Los textos condenan de forma contundente al coronel libio y advierte de cómo está estimulando el terrorismo: 
Y no cabe tampoco ninguna duda de que de Libia salen, como mínimo, estímulos para el terrorismo internacional. Prueba de ello son los discursos amenazantes del coronel, que, si bien poseen escasa credibilidad en cuanto a su capacidad de emprender acciones bélicas ofensivas, contienen llamamientos a unas movilizaciones populares que, en el campo abonado del activismo islámico, caen como directas convocatorias a la acción terrorista ${ }^{37}$.

EE.UU. ha actuado mal porque con su comportamiento, "fortalecen a Gaddafi". Abogó así por una política europea que siguiendo y respetando el derecho internacional, "ayude a la consolidación de las fuerzas de racionalidad y moderación, frente a la ola fanática que Gaddafi se esfuerza por alentar".

El siguiente editorial recuperó el tono de condena contra EE.UU. del primero de nuestro análisis, y lo elevó, dado que se lleva la pieza a la portada, aspecto éste que no es baladí38. El título del mismo, "La guerra a las puertas de casa", parece estar tomado de unas declaraciones del presidente italiano, Bettino Craxi ${ }^{39}$. Encontramos un número muy elevado de adverbios y adjetivos, muy superior al de los otros diarios. Podemos decir, sin errar, que el diario bombardea gramaticalmente a EE.UU. pues no es una crítica sino un ataque.

Para el diario los hechos merecían una condena sin paliativos y ello aunque se demostrase la participación de Libia en actos terroristas, aspecto este en el que el diario incurre en varias contradicciones: advierte que no está demostrado, para decir que es algo evidente, y más adelante volver a decir que en el hipotético caso de que se demostrara no cabría justificación. Incluimos uno de los párrafos al respecto:

Hay que insistir en que la Administración estadounidense no ha sido capaz hasta ahora en ningún momento de exhibir pruebas convincentes de la culpabilidad directa del Gobierno libio en las acciones terroristas recientes, si bien sea del común acuerdo el hecho de que Libia, de un modo u otro, se halla detrás de esos atentados ${ }^{40}$.

Estamos ante una ofensa al derecho internacional, algo que es el núcleo argumental del diario en todos los editoriales, y además ante "un hecho execrable". La utilización de la fuerza por parte de la VI Flota "mediante métodos tan expeditivos -tan repugnantes o más que los que pretende evitar-", compromete la paz en el mundo y no es más que "una demostración abusiva y cruel del poderío militar americano, exportando una guerra más hacia áreas alejadas de su territorio". El diario quiso ser rotundo en la condena hacia la Administración Reagan, y para que los textos fueran más comprensibles, se sirvió de metáforas cinematográficas:

Entre los muchos peligros añadidos que la acción americana encierra está el de que arroje arrogancia sobre arrogancia en la ya abultada prosopopeya bélica del presidente Reagan y éste se sienta autorizado a prácticamente todo: bombardear Libia primero, invadir Nicaragua después y sabe Dios qué otra odisea a lo Rambo más tarde ${ }^{41}$.

El siguiente editorial no varía en fondo y forma del anterior ${ }^{42}$. Fomentó el alarmismo y una visión apocalíptica en torno a las represalias de Gaddafi y a en qué situación iban a quedar los aliados. La condena es dura y recurre a un lenguaje contun- 
dente: adverbios, ocho en total, y adjetivos de valoración negativa contra los EE.UU. Para el diario "Sorprende el primitivismo del pensamiento político que inspira la actitud de Washington".

Reagan se ha convertido en "el nuevo gendarme del Mediterráneo", por ello insistió en que EE.UU. actuaba lejos de su territorio, alejándose también el diario del análisis que merecían los hechos, que van más allá de la distancia geográfica. Y Washington no había bombardeado Libia para poner fin al terrorismo, según la cabecera, pero tampoco explicó cuáles podrían ser las razones. No fue claro en la argumentación. Señaló que Libia no era el principal promotor del terrorismo, lo eran más Siria, Irán y Líbano y comparó la acción de la VI Flota con las represalias israelíes contra los palestinos:

Y, si se quiere extender el análisis hacia la OLP, no podría hacerse sin condenar también los actos de terrorismo de Estado a los que Israel nos tiene acostumbrados con sus represalias contra los campos palestinos (en las que parece haberse inspirado la última aventura de Reagan). Nos encontraremos así ante la difícil tarea de definir la divisoria entre el terrorismo y la guerra ${ }^{43}$.

EE.UU. había escrito "una página negra en su historia política". La actitud de Washington, o como dijo el diario, "el ensayo de Reagan", "rompe con una lógica política enraizada en Europa". La actitud de Reagan beneficia a los terroristas, debilita o anula a Europa, predispone a una guerra y pone en peligro las conversaciones de Ginebra, y por ende, la Guerra Fría.

En definitiva, son todavía muchas las interrogantes abiertas tras el ataque del martes. No sabemos cuál será la reacción próxima de Gaddafi, el grado de unidad que el mundo árabe pueda obtener en torno a él, las consecuencias para la política de los países productores de petróleo y la evolución en las relaciones entre las naciones aliadas europeas y un socio tan arrogante como el del otro lado del océano. Algo es seguro: desde el martes ha aumentado la inseguridad en el Mediterráneo y con ello la frustración de Europa ${ }^{44}$.

En la siguiente pieza se condenó el bombardeo estadounidense sobre Trípoli como respuesta al atentado en la discoteca de Berlín ${ }^{45}$. Por un lado, por los argumentos esgrimidos por Washington que implican a Libia en el mismo. Por otra parte, porque no son las formas que aducirían tanto la opinión pública norteamericana más sensata como la propia Europa. Pero la razón principal para el diario sobre la ilegitimidad del bombardeo tiene su base en el concepto de terrorismo: "¿Qué se entiende por terrorismo? La interpretación de este término, no sólo por parte de la Administración, sino entre sectores de la opinión pública de EE.UU., difiere mucho de la lógica -y de la sensibilidad- europea". Así las cosas, ¿es terrorismo lo que hace Israel o el espionaje francés? Para el rotativo, no se puede "meter todo en el mismo saco". Criticó al gobierno español por la opacidad con que estaba informando de los hechos y animó a Europa a actuar y a reivindicar una manera de afrontar las crisis que dejase constancia de su superioridad: "Una solución es posible, pero solamente por el camino de propuestas y actos políticos. Europa tiene que saber encarnar hoy esa primacía de la política. Será así fiel a lo mejor de su historia”. 
Acometemos la descripción del último editorial analizado en el diario ${ }^{46}$. La ONU, el Tercer Mundo, Estados Unidos y Europa, fueron los núcleos argumentales del texto, que condenó el uso de la fuerza como solución al terrorismo internacional y apeló a la defensa de la ONU, "Las decisiones de la ONU, aunque no logren ser operativas, tienen un peso moral indiscutible" exculpando al organismo internacional garante de la resolución de conflictos, de su falta de inoperancia porque "la división del mundo en bloques militares ha privado de eficacia al Consejo de Seguridad de la ONU".

\section{Conclusiones}

No detectamos un enmarcado de acontecimientos que persiga reducir el conflicto bélico entre EE.UU. y Libia, sino dirigido a narrar los hechos desde una postura concreta. En el caso de La Vanguardia, el especial no reflejó la realidad de lo ocurrido al rebajar el conflicto bélico a "crisis". En titulares recurrió a términos como "acción militar", "crisis", "intervención militar" y "ataque militar". Los protagonistas de titulares y antetítulos fueron por este orden, EE.UU., Washington, La Casa Blanca, el Pentágono, Reagan y la VI Flota, que figuraron en un total de veintiséis ocasiones; mientras que los términos Libia y Gaddafi aparecieron en veintidós titulares. También obtuvo una representación significativa el término "terrorismo", pero en un número mucho menor a los otros vocablos. Nos hallamos ante una cobertura episódica que remite a una descripción del conflicto pero evitando las connotaciones bélicas y sobre todo, evitando referirse a Reagan o a EE.UU.

El discurso editorial, adopta una actitud crítica, que persigue construir argumentos apelando a la razón, de forma fría y serena, con un lenguaje moderado, sin incurrir en contradicciones. Se trata de juicios duros, generalmente hacia Gaddafi, pero construidos en torno a manifestaciones directas, sencillas, sin retórica, metáforas, ni partidismos. Parece que la función de los textos es explicativa, dejando que sea el propio lector quien determine el veredicto.

$A B C$ fue el diario menos ambiguo, tanto en especiales como en titulares, en cuanto a incluir sin reparos los distintos bombardeos de EE.UU. sobre Trípoli, al enfrentamiento bélico y a la "guerra abierta" que mantenían Reagan y Gaddafi. El mayor número de términos es para EE.UU., Reagan y la VI Flota, en doce ocasiones, mientras que Libia y Gaddafi aparecen en diez. La cobertura es, en general, menos episódica y más temática. $A B C$ quiere dejar constancia de la supremacía militar estadounidense, criticar al gobierno español y destapar aquellos aspectos de la URSS que le ayuden a enarbolar un discurso sobre su posición ante la Guerra Fría y el bloque soviético.

En los editoriales emite su propia sentencia sin dejar que el lector juzgue o reflexione. Con grandes dosis de ironía, utilizó una función interpretativa y en mayor medida, una llamada a actuar, que no es otra que respaldar a Estados Unidos. Emitió 
juicios categóricos y cerrados. Nos hallamos ante editoriales combativos, con una posición ideológica clara de contraposición al gobierno del momento.

En El País encontramos una cobertura temática, sofisticada y abstracta, que sí da cuenta de la gravedad del conflicto, -sobre todo en el especial, excesivo en fondo y forma- pero que recurre a algunos elementos desproporcionados, como el nombre dado al especial durante toda la cobertura, "guerra en el Mediterráneo", la foto de Franco y Eisenhower en el aeropuerto de Torrejón en 1959, el editorial de portada, y también por la ambigüedad de titulares que no remiten de forma tan nítida a los hechos: "demostración práctica del poderío militar", "bombarderos norteamericanos atacaron", "temerarias acciones de guerra". En doce ocasiones utilizaron términos relacionados con EE.UU. y en trece Libia y Gaddafi, concretamente el apellido del coronel libio aparece en un número mucho mayor al de las otras cabeceras. El grado de comentario de los titulares es mayor, el protagonismo de España e Italia está muy presente, y de su lectura se desprende una inclinación a despertar el miedo a que España pueda ser víctima directa de las acciones militares de EE.UU.

En el apartado editorial, El País adoleció de argumentos sólidos y de agudeza crítica. La base argumentativa no es clara: ataca y reprueba el bombardeo estadounidense, pero no lo hace a través de manifestaciones que ofrezcan un análisis ponderado, por ello, no hay condena, o no es tan evidente, hacia Gaddafi, ni tampoco es nítido en la crítica hacia Europa: el europeísmo excesivo le resta mucha credibilidad. Mueve a la acción y parece sentir cierta obsesión por EE.UU., de ahí que incurra en un tono tan iracundo y parcial. Al igual que en $A B C$, son juicios severos y cerrados, no análisis que inviten a la reflexión o que permitan que el lector elabore su opinión en torno a datos.

La operación "El Dorado Canyon" no fue una guerra, sino un enfrentamiento bélico entre dos países. En este sentido, parece que La Vanguardia, fue el único diario que no quiso aprovechar el conflicto para hacer propaganda ni para llevar a cabo acciones de framing. Asimismo, el diario anticipó, y denunció, el doble rasero de los países europeos que mantenían relaciones de interés con el régimen libio y practicaban posturas ambiguas e hipócritas. Posturas, no debemos olvidar, que se mantuvieron durante años con el coronel libio durante todas sus visitas a Europa, donde fue recibido con gran solemnidad.

$A B C$ y El País sí hablaron de guerra sin tapujos e incluso recurrieron a elementos que sirvieran de respaldo para su posición, pero no parece, o al menos no se desprende del presente estudio, que fuera en aras de atender fines periodísticos, sino objetivos de persuasión. En la cobertura de un conflicto bélico, los medios están llamados a practicar un mayor rigor y a sacrificar sus necesidades editoriales, porque sólo así se garantiza una opinión pública libre y reflexiva. Pero la historia confirma que todas las guerras y conflictos bélicos han sido el caldo de cultivo de los medios para practicar propaganda, agitar a la población y crear bandos.

Gaddafi falleció en octubre de 2011, cerca del Golfo de Sirte, escenario del conflicto bélico de 1986. Fue una de las primeras víctimas de las revueltas de la primavera 
árabe. Las lamentables imágenes de su linchamiento fueron mostradas hasta la saciedad por todos los medios de comunicación. Se confirma el carácter cíclico de los medios, y su actitud, imprudente e irresponsable, con respecto a personajes, otrora defendidos, después humillados. Y se confirma, cómo los medios pueden perder el sentido de la realidad ante la tragedia y el fracaso que supone cualquier conflicto bélico.

\section{Referencias bibliográficas}

ENTMAN, R. M. (2007). "Framing Bias: Media in the Distribution of Power". En: Journal of Communication, $\mathrm{n}^{\circ}$ 57, pp. 163-173.

FERNÁNDEZ BARRERO, Ma A. (2003). El editorial. Un género periodístico abierto al debate, Sevilla: Comunicación Social.

IGARTUA, J. J. y HUMANES, M. L. (2004). Teoría e investigación en comunicación social, Madrid: Síntesis.

IYENGAR, S. y OTTATI, V. (1994). "Cognitive perspective in political psychology. En: WYER, R. S. y SRULL, T.S. (Eds.), Handbook of social cognition. Hillsdale, NJ: Lawrence Erlbaum Associates. pp. 143-187.

MARTÍN MUÑOZ, G. (1994). "El sueño del coronel Ghadafi”. En: Historia 16, no 222, 1994, pp. 19-26.

McCOMBS, M. y SHAW, D. L. (1972). "The agenda-setting function of the mass media”. En: Public Opinion Quarterly, no 36, pp. 176-185.

McCOMBS, M. (1996). "Influencia de las noticias sobre nuestras imágenes del mundo". En: BRYANT, J. y ZILLMANN, D. (comps.). Los efectos de los medios de comunicación. Investigaciones y teorías, Barcelona: Paidós. pp. 13-34.

McCOMBS, M. y GHANEM, S. (2001). "The convergence of Agenda Setting and Framing". En: REESE, S. D., GANDY, O. H., GRANT, A. E., (eds.). Framing public life. Perspectives on media and our understanding of the social world, Mahwah: Lawrence Erlbaum. pp. 67- 81.

MILLER, M. M. y RIECHERT, B. P. (2003). "The Spiral of opportunity and Frame resonance: Mapping the Issue Cycle in news and Public Discourse". En REESE, S. D., GANDY, O. H., GRANT, A. E., (eds.). Framing public life. Perspectives on media and our understanding of the social world, Mahwah: Lawrence Erlbaum. pp. 107-121.

MOUSTAOUI SRHIR, A. (2011). "La construcción del sujeto y auto-representación en los discursos de Muaamar Al Gaddafi: Hacia la auto-deslegitimación". En: Discurso \& Sociedad, Vol. 5, n 2, pp. 299-332.

PACK, J. (2013). "Exit Gaddafi: the hidden history of the Libyan revolution". En: Middle East Journal, Vol. 67, nº 2, pp. 319-322.

REAGAN, R. (1991). Una vida americana. Barcelona: Plaza y Janés/Cambio 16.

SANTAMARÍA, L., CASALS, M. J. (2000). La opinión periodística. Argumentos y géneros para la persuasión. Madrid: Fragua. 
SEMETKO, H. A. y VALKENBURG, P. M. (2000). "Framing European politics: A content analysis of press and television news". En: Journal of Communication, spring, pp. 93-109.

STANIK, J. T. (2003). El Dorado Canyon: Reagan's Undeclared War With Qaddafi. Annapolis, Maryland: Naval Institute Press.

\section{Notas}

1. Hay estudios recientes que se han ocupado de la figura del coronel Gaddafi una vez asesinado, así como obras que se han ocupado de su papel en la política de Libia, sus relaciones con los países europeos y de Oriente Medio, así como de sus conexiones con el terrorismo internacional.

2. Ronald Reagan, cfr. "La aviación de EE.UU. bombardea Libia y centra su ataque en el cuartel de Gadafi”, ABC, 15/04/1986, p. 1.

3. Igartua y Humanes consideran la $\mathrm{T}^{\mathrm{a}}$ del Framing como subordinada a la Agenda Setting. Cfr. (2004: 255-256).

4. RAMOS, R. "Washington se enfrenta a Trípoli porque sabe que Moscú no moverá un dedo para ayudar a Gaddafi”, La Vanguardia, 26/03/1986, p. 6.

5. Ibidem.

6. RAMOS, R. "El presidente Reagan jugó la partida contra Libia con cuatro ases en la mano", La Vanguardia, 17/04/1986, p. 4.

7. RAMOS, R. “EE.UU. no responderá a cada uno de los atentados pero se reserva su actuación”, La Vanguardia, 18/04/1986, p. 14.

8. Cfr. "La inquietante opción bélica”, La Vanguardia, 26/03/1986, p. 6, (editorial).

9. "El factor del terrorismo", La Vanguardia, 27/03/1986, p. 6, (editorial).

10. "La reunión de La Haya", La Vanguardia, 14/04/1986, p. 4. (editorial).

11. “La crisis del Mediterráneo", La Vanguardia, 15/04/1986, p. 4. (editorial).

12. Ibidem.

13. "Una prueba de fuerza", La Vanguardia, 16/04/1986, p. 4. (editorial).

14. "El fondo de una crisis", La Vanguardia, 17/04/1986, p. 4. (editorial).

15. Ibidem.

16. “Cohesión contra el terrorismo”, La Vanguardia, 18/04/1986, p. 4. (editorial).

17. Ibidem.

18. Ibid.

19. Ibid.

20. CARRASCAL, J. M. “Alarma mundial por la guerra abierta Libia-USA”, ABC, 25/03/1986, p. 21.

21. CARRASCAL, J. M. "Seleccionados los blancos del ataque USA a Libia”, ABC, 13/04/1986, p. 1. 
22. "Guerra en Libia", ABC, 15/04/1986, p. 15, (editorial).

23. Cfr. CARRASCAL, J. M. "Reagan decidió atacar cuando tuvo "pruebas irrefutables" contra Gadaf", ABC, 16/04/1986, p. 24.

24. “Grave confrontación”, 25/03/1986, ABC, p. 11, (editorial).

25. "Españoles en Libia”, 13/04/1986, ABC, p. 19, (editorial).

26. “Guerra en Libia”, ABC, 15/04/1986, p. 15, (editorial).

27. "La crisis mediterránea", ABC, 16/04/1986, p. 15, (Editorial).

28. Ibidem.

29. "El fin de la comedia", ABC, 18/04/1986, p. 15, (Editorial).

30. El diario utilizó las mayúsculas para todo el especial y así lo reproducimos.

31. "La VI Flota ataca de nuevo una base de misiles libia y alcanza otras dos patrulleras", El País, 26/03/1986, p. 1

32. "Los aviones partieron del Reino Unido de la VI Fiota”, El País, 15/04/1986, p. 3.

33. Cfr: El País, 16/04/1986, pp. 4 y 8.

34. “Temerarias acciones de guerra”, El País, 26/03/1986, p. 10, (editorial).

35. Ibidem.

36. “Gaddafi amenaza”, El País, 1/04/1986, p. 10, (editorial).

37. Ibidem.

38. "La guerra a las puertas de casa", El País, 15/04/1986, portada y p. 10, (editorial). "Llevar un editorial a portada es frecuente en los periódicos con notable intención política o educativa”, FERNÁNDEZ BARRERO, (2003: 47).

39. Cfr. "Bettino Craxi afirma que 'Italia no quiere guerras a las puertas de su casa' y ofrece su mediación”, La Vanguardia, 26/03/1986, p. 11.

40. “La guerra a las puertas de casa”, El País, 15/04/1986, portada y p. 10, (editorial).

41. Ibidem.

42. “Después del bombardeo”, El País, 16/04/1986, p. 16, (editorial).

43. Ibidem.

44. Ibid.

45. "Europa y el conflicto libio”, El País, 17/04/1986, p. 10, (editorial).

46. “De espaldas al derecho internacional”, El País, 2/05/1986, p. 10. 


\section{La autora}

Profesora de la Universidad de Valladolid (2004) “Campus María Zambrano” y miembro del "Grupo de Investigación en Comunicación Audiovisual e Hipermedia", en la misma universidad. Doctora en Periodismo por la Universidad de Valladolid (2009) y Máster en Comunicación Corporativa y Publicitaria por la Universidad Complutense de Madrid, (1999). Es investigadora del Instituto Franklin de Investigación en Estudios norteamericanos de la Universidad de Alcalá, y sus líneas de investigación versan sobre el periodismo de investigación de base histórica, (Estados Unidos y la Guerra Fría), la historia de la comunicación social y los efectos de los medios. Sus publicaciones analizan la imagen mediática de los Estados Unidos y algunas de las crisis e intervenciones bélicas más importantes de finales del siglo XX. 